\title{
PENGARUH KETINGGIAN PERANGKAP FEROMON DALAM MENGENDALIKAN \\ KUMBANG TANDUK (Oryctes rhinoceros L.) DI PERKEBUNAN PT HERFINTA
}

\author{
Widya Lestari, Siti Hartati Yusida Saragih, Hasiyan Harahap \\ Program Studi Agroteknologi, Fakultas Sains dan Teknologi, Universitas Labuhanbatu \\ Jl. SM. Raja No. 126A Rantauprapat, Sumatera Utara \\ e-mail :widyalestari1688@gmail.com
}

\begin{abstract}
Oryctes rhinoceros L. is one of the major pest of oil palm plantation which can cause damage to 69\%. Attacks sheath of leaf that has not been opening and the growing point, this cause disruption of plant growth. Conventional control usually used by the farmer is by using chemical insecticides which can result negative impacts to humans and environment. The use of aggregation pheromons is an alternative control to reduce the population of Oryctes rhinoceros in the field which save for humans and environment.. The use of aggregation pheromones is an alternative control to reduce the Oryctes rhino population in the field which saves humans and the environment. This study aims to determine the high effectiveness of pheromone traps in trapping Oryctes rhinoceros L. This research was conducted in the oil palm plantation of PT. Herfinta Farm \& Plantion, Tanjung Medan Village, People's Village District, Labuhan Batu Regency, South Sumatra, North Sumatra. The research was conducted from May to June 2020. The number of trapped horn beetles was observed. The highest number of trapped beetles was obtained by male beetles in treatment P4 $2.5 \mathrm{~m}$, namely 1031 beetles, while the number of beetles at P3 2 m was 659 beetles, while the number of beetles at P2 $1.5 \mathrm{~m}$ was 308 beetles while the number of beetles without treatment was P1 ( Control), namely 75 Beetles.
\end{abstract}

Key words: Oryctes rhinoceros, palm plantation, pheromons

\section{PENDAHULUAN}

Kumbang tanduk merupakan salah satu hama utama pada perkebunan kelapa sawit muda, terutama pada areal replanting, permasalahan hama ini semakin penting karena pemanfaatan tandan kosong kelapa sawit pada areal tanaman sawit sebagai mulsa dan pengganti pupuk non organik. Pemberian tankos ini memberikan dampak negatif, yaitu sebagai tempat berkembangbiaknya kumbang tanduk, sehingga populasi hama ini meningkat dan menimbulkan kerusakan yang lebih serius (Sudharto, 2000).

$$
\text { Masalah kumbang tanduk }(O \text {. }
$$

rhinoceros L) semakin berkembang dengan adanya pemanfaatan tandan kosong kelapa sawit pada gawangan maupun pada sistem lubang tanam besar. Pada saat mulsa tandan kosong kelapa sawit ini mulai membusuk menjadi tempat yang baik bagi perkembangbiakan $O$. rhinoceros $\mathrm{L}$ (Chenon dkk., 1997).

Hama ini menyebar hampir di seluruh provinsi yang ada di Indonesia karena ketersedian inang dan tumpukan bahan organik dilapangan sebagai tempat perkembangbiakan dan makanan larva. Darmadi (2008) menyatakan bahwa hama ini menyerang tanaman kelapa sawit yang ditanam di lapangan sampai umur 2,5 tahun dengan merusak titik tumbuh sehingga terjadi kerusakan pada daun muda. Kumbang tanduk 
pada umumnya menyerang tanaman kelapa sawit muda dan dapat menurunkan produksi tandan buah segar (TBS) pada tahun pertama menghasilkan hingga 69\%, bahkan menyebabkan tanaman muda mati mencapai 25\%. (negatif) yang ditimbulkan akibat penggunan senyawa kimia sintetik maka perlu diupayakan metode yang aman untuk mengendalikan $O$. rhinoceros sebagai pengendalian altrnatif yaitu penggunaan feromon agregasi.

Pengendalian kumbang tanduk (Oryctes rhinoceros L) sangat penting salah satunya dengan menggunakan perangkap feromon sebagai insektisida alami, selain alami feromon juga ramah lingkungan, dan lebih murah dibandingkan dengan pengendalian konvensional. Feromon adalah sejenis zat kimia yang berfungsi untuk merangsang dan memiliki daya pikat seksual pada jantan maupun betina. Zat ini berasal dari kelenjar endokrin dan digunakan oleh makhluk hidup untuk mengenali sesama jenis, individu lain, kelompok, dan untuk membantu reproduksi. Feromon merupakan bahan yang mengantarkan serangga pada pasangan seksualnya, sekaligus mangsa, tanaman inang, dan tempat berkembang biaknya. Komponen utama feromon sintetis ini adalah etil-4 metil oktanoat (PPKS, 2008).

Feromon adalah substansi kimia yang dilepaskan oleh suatu organisme kelingkungannya untuk mengadakan komunikasi secara intraspesifik dengan individu lain. Feromon bermanfaat dalam monitoring populasi maupun pengendalian hama. Alouw (2006) bahwa dengan penggunan perangkap feromon selama 1 bulan dapat memerangkap sebanyak 27 ekor/ha/bulan. Hasil penelitian Rahutomo (2008) dalam 1 bulan dapat memerangkap 120 ekor kumbang tanduk dan tergantung banyaknya populasi kumbang di lapangan, dengan tingkat keampuhan mencapai $95 \%$ dalam memerangkap kumbang. Feromon agregasi adalah jenis feromon yang dikeluarkan untuk menarik serangga jantan maupun betina agar berkelompok (Klowden, 2002).

\section{Tujuan}

Penelitian ini bertujuan untuk menguji tingkat ketinggian perangkap feromon yang efektif untuk memerangkap Oryctes rhinoceros $\mathrm{L}$.

\section{METODE PENELITIAN}

Penelitian dilaksanakan di PT. Herfinta Farm \& Plantion Desa Tanjung medan Kecamatan kampung rakyat Kabupaten Labuhan Batu Selatan Sumatera utara. Waktu pelaksanaannya mulai Mei 2020 hingga Juni 2020. Adapun bahan-bahan yang dipergunakan dalam penelitian ini adalah: Feromon ( etil- 4 metil oktanoat ), Bambu, Ember, Paku, Tali. Sedangkan alat yang dipergunakan sebagai berikut : Gergaji, Parang, Pisau.

Metode penelitian adalah Rancangan Acak Kelompok (RAK) dengan 3 perlakuan dan 4 Afdeling sebagai kelompok sehingga di 
dapat 12 unit percobaan. Penempatan perangkap dilakukan secara acak dinama pada satu desa sebanyak 3 perangkap yang mempunyai ketinggian yang berbeda yaitu 1,5 meter, 2 meter dan 2,5 meter dengan jarak antar perangkap 100 meter. Penelitian dilakukan pada areal kelapa sawit yang belum menghasilkan (TBM) dengan umur tanaman 2.5 tahun.

Adapun perlakuan tinggi tiang perangkap sebagai berikut :

P1h : Tinggi perangkap 1,5 meter $\mathrm{P} 2 \mathrm{~h}$ : Tinggi perangkap 2 meter P3h : Tinggi perangkap 2,5 meter

\section{Pelaksanaan}

Pelaksanaan dalam penelitian ini meliputi : 1) Survei lokasi penelitian yang betujuan untuk mengetahui keedaan lokasi yang akan dijadikan sebagai tempat pelaksanaan penelitian. 2) Deskripsi lokasi penelitian. 3) Pembuatan perangkap. 4) Pemasangan perangkap di lapangan.

\section{Pengamatan}

Parameter yang diamati meliputi : waktu pertama O.rhinoceros. L terperangkap (hari), jumlah O.rhinoceros L yang terperangkap (ekor)

\section{HASIL DAN PEMBAHASAN}

Waktu pertama O.rhinoceros. L terperangkap (hari)

Pengamatan waktu pertama $O$. rhinoceros terperangkap setelah dianalisis secara statistik menggunakan sidik ragam menunjukkan bahwa ketinggian perangkap tidak memberikan pengaruh antar perlakuan dalam memerangkap O.rhinoceros. L

\begin{tabular}{ll}
\hline Tinggi perangkap $(\mathrm{m})$ & Rata-rata (hari) \\
\hline 1,5 & 1.25 \\
2 & 1.00 \\
2,5 & 1.25
\end{tabular}

Tabel 1. Waktu pertama O.rhinoceros. L terperangkap (hari)

Tabel 1 menunjukkan tinggi perangkap 1,5 meter dan 2,5 meter mempunyai waktu yang sama O.rhinoceros mulai masuk perangkap yaitu 1,25 hari, sedangkan tinggi perangkap 2 meter 1 hari. Hal ini kerena feromon agregasi yang digunakan pada penelitian sudah mulai menguap atau mengeluarkan bau pada saat pemasangan perangkap dilakukan. Juga tidak terlepas dari pengaruh faktor lingkungan terutama temperatur udara rata-rata $29^{\circ} \mathrm{C}$ saat penelitian hal ini yang menyebabkan pelepasan senyawa pada feromon berlansung cepat. Chenon dkk., (1997) menyatakan bahwa semakin tinggi temperatur maka pelepasan senyawa yang terdapat pada feromon akan semakin cepat dan lebih cepat diterima kumbang melalui penerima bau yang berada di antena (sensillum) oleh kumbang O.rhinoceros.

Hasil pengamatan jumlah perangkap menunjukkan bahwa perangkap yang dihasilkan selama 1 bulan. Dengan rataan jumlah perangkap dapat dilihat pada tabel berikut ini: 
Tabel 5.1.1. Rataan Jumlah Kumbang Terperangkap Jumlah Kumbang Keseluruhan

\begin{tabular}{lccc} 
Perlakuan & & & Total \\
\hline P1 0 m & B & J & \\
P2 1,5 m & 204 & 104 & 308 \\
P3 2 m & 421 & 237 & 659 \\
P4 2,5 m & 674 & 357 & 1031
\end{tabular}

Keterangan: B : Betina J : Jantan

Berdasarkan hasil dari pengamatan penelitian diatas kesimpulan bahwa jumlah kumbang terperangkap yang tertinggi diperoleh Kumbang Betina pada perlakuan P4 2,5 m yaitu 1031 kumbang, sedangkan jumlah kumbang pada P3 2 m yaitu 659 kumbang, kemudian sedangkan jumlah kumbang pada P2 1,5 m yaitu 308 kumbang sedangkan jumlah kumbang tanpa perlakuan P1 (Kontrol) yaitu 75 Kumbang. Banyaknya kumbang tanduk betina yang terperangkap pada semua perlakuan ketinggian perangkap disebabkan karena daya tarik feromon secara signifikan lebih kuat terhadap imago $O$. rhinoceros betina dari pada yang jantan. Hasil kajian ini mendukung laporan Sudharto et al. (2008) bahwa feromon tersebut menarik 21 $31 \%$ imago jantan dan 67- $79 \%$ imago betina. Feromon sintetik etil -4 metil oktanoate memang dikembangkan dari isolasi feromon imago $O$. rhinoceros jantan sehingga kumbang betina lebih banyak tertarik.

Hal tersebut di atas diperkuat oleh pendapat Rahutomo (2008), yang menyatakan bahwa senyawa kimia etil methylactonoat pada feromon agregasi sintetik hanya mampu bertahan selama 3 bulan di lapangan, jika disimpan terlalu lama akan habis menguap. (Alouw, 2018) menambahkan keberhasilan penggunaan feromon dipengaruhi oleh penguapan bahan kimia, kepekaan penerima, jumlah dan bahan kimia yang dihasilkan dan dibebaskan persatuan waktu, kecepatan angin dan temperatur. Suhu yang tinggi dan kecepatan angin yang sesuai mempercepat penguapan feromon untuk menyebar sehinggga lebih cepat untuk merangsang $O$. rhinoceros untuk mencari asal sumber feromon tersebut (Fauzana, 2019). Berkurangnya populasi $O$. rhinoceros pada areal pengamatan akibat penangkapan juga sangat mempengaruhi jumlah tangkapan O.rhinoceros tiap minggunya.

Menurut (Sahetapy, 2018) Penggunaan feromon dapat mengakibatkan penurunan populasi O.rhinoceros di lapangan pada generasi berikutnya, hal ini disebabkan oleh adanya perubahan laju kelahiran. Salah satu faktor utama penentu laju kelahiran adalah rasio seks. Rasio seks pada kebanyakan kumbang tanduk populasi adalah $1: 1$, jantan terhadap betina dan jantan

\section{KESIMPULAN DAN SARAN KESIMPULAN}

Dari penelitian yang telah 
dilaksanakan dapat diambil kesimpulan bahwa ketinggian perangkap 2,5 meter yang lebih baik dalam memerangkap kumbang tanduk (O.rhinoceros) di areal kebun kelapa sawit yang belum menghasilkan. Total kumbang yang terperangkap 1031 ekor, yang banyak terperangkap adalah kumbang betina. Penambahan tinggi perangkap tidak menberikan pengaruh terhadap pemerangkapan kumbang O.rhinoceros.

\section{SARAN}

Agar dilakukan penelitian lebih lanjut di lapangan tentang pengamatan waktu feromon agregasi bisa bertahan untuk dapat menarik O.rhinoceros terutama pada areal replanting.

\section{DAFTAR PUSTAKA}

Alouw, 2018. "Feromon Dan Pemanfaatannya Dalam Pengendalian Hama Kumbang Kelapa Oryctes Rhinoceros (Coleoptera: Scarabaeidae)." Feromon Dan Pemanfaatannya Dalam Pengendalian Hama Kumbang Kelapa Oryctes Rhinoceros (Coleoptera: Scarabaeidae), no. 32: 12-21. https://doi.org/10.21082/bp.v0n32.200 7.12-21.

Chenon. D, C.U. Ginting dan A. Sipayung. 1997. Pengendalian hama Oryctes dan ulat pemakan daun kelapa sawit secara terpadu. Pertemuan teknis kelapa sawit. Medan

Darmadi. 2008. Hama dan penyakit kelapa sawit. http//www,isg.org/ecology/sip?=it.Dia kses pada 20 Februari 2020.
Fauzana, 2019. "Population Fluctuations Oryctes Rhinoceros L. Beetle in Plant Oil Palm (Elaeis Guineensis Jacq.) Given Mulching Oil Palm Empty Bunch." CROPSAVER - Journal of Plant Protection 1 (1): 42. https://doi.org/10.24198/cropsaver.v1i 1.16998.

Klowden, M.J. 2002. Physiological system in insects. Acad press. London.

Pusat Penelitian Kelapa Sawit. 2008. Pertemuan teknis kelapa sawit. PPKS.Medan

Rahutomo, S. 2008. Veromonas ampuh basmi hama kumbang sawit. Tecnologi Indonesia, mapiptek. E-megazin, edisi 17 April 2008.Jakarta. Diakses 1 mei 2012.

Sahetapy, 2018. "Uji Efektivitas Perangkap Feromon Terhadap Hama Oryctes Rhinoceros L. Dan Intensitas Kerusakan Pada Tanaman Kelapa Di Desa Latuhalat, Kecamatan Nusaniwe, Pulau Ambon." Agrikultura 29 (1): 19. https://doi.org/10.24198/agrikultura.v2 9i1.16922.

Sudharto Ps, A. Susanto, Z.A. Harahap, \& E. Purnomo. 2000. Pengendalian Kumbang Tanduk Oryctes rhinoceros pada Tumpukan Tandan Kosong Kelapa Sawit. Pertemuan Teknis Kelapa Sawit. Medan, Oktober 2000. 